\title{
Coronary Flow Reserve Estimated by Positron Emission Tomography to Diagnose Significant Coronary Artery Disease and Predict Cardiac Events
}

\author{
Masanao Naya, MD, PhD; Nagara Tamaki, MD, PhD; Hiroyuki Tsutsui, MD, PhD
}

\begin{abstract}
Coronary artery disease (CAD) is a major cause of death in Japan. Coronary angiography is useful to assess the atherosclerotic burden in CAD patients, but its ability to predict whether patients will respond favorably to optimal medical therapy and revascularization is limited. The measurement of the fractional flow reserve with angiography is a well-validated method for identifying ischemic vessels. However, neither an anatomical assessment nor a functional assessment can delineate microvasculature or estimate its function. The quantitative coronary flow reserve (CFR) estimated from sequential myocardial perfusion images obtained by positron emission tomography (PET) during stress provides an accurate index of hyperemic reactivity to vasodilatory agents in the myocardium. In fact, there is growing evidence that the CFR reflects disease activity in the entire coronary circulation, including epicardial coronary artery stenosis, diffuse atherosclerosis, and microvascular dilatory function. Importantly, reduced CFR is observed even in patients without flow-limiting coronary stenosis, and its evaluation can improve the risk stratification of patients at any stage of CAD. This review focuses on the application of CFR estimated by cardiac PET for the diagnosis and risk stratification of patients with CAD. (Circ $J$ 2015; 79: 15-23)
\end{abstract}

Key Words: Coronary artery disease; Coronary circulation; Positron emission tomography

$\mathbf{R}$ ecent decades have seen steady improvements in estimating myocardial blood flow (MBF) with advanced positron emission tomography (PET) scanners and kinetic models. ${ }^{1,2}$ Accurate, robust, and well-validated models enable us to use MBF in addition to perfusion images for the diagnosis and risk stratification of coronary artery disease (CAD). Although the evidence level to assess the severity of ischemia by semiquantitative visual imaging is high enough for the diagnosis and management of CAD, this approach cannot capture microcirculatory vascular function. Reduced coronary flow reserve (CFR) may reflect abnormalities of microvascular function, flow-limiting coronary stenosis, and diffuse atherosclerosis. Thus, CFR dramatically improves diagnostic value and risk stratification in patients with suspected CAD. This review focuses on the application of CFR estimated by cardiac PET for the diagnosis and risk stratification in patients with CAD.

\section{PET Stress Perfusion Imaging for the Diagnosis of CAD}

Stress perfusion imaging by PET discriminates patients who have flow-limiting obstructive coronary artery stenosis from non-obstructive stenosis with sensitivity of 0.90 , specificity of
0.89 , positive predictive value of 0.94 , negative predictive value of 0.73 , and accuracy of $0.90 .^{3-7}$ Likewise, stress MRI and stress CT myocardial perfusion images have shown high diagnostic value..$^{8,9}$ One limitation of stress PET and SPECT compared with MRI and CT perfusion imaging is that they often uncover only the coronary territories supplied by the most severe stenosis and, consequently, they are less able to accurately delineate the extent of obstructive angiographic CAD, especially in the setting of multivessel CAD. ${ }^{10-15}$ This is related to the methodology of PET, which delineates the lowperfusion area against a relatively well-perfused area whereas CT and MRI perfusion capture the subendocardial low-perfusion area (ischemia). PET measurement of left ventricular (LV) cavity values on stress-summed imaging and the delta LV ejection fraction $(\mathrm{EF})$ at rest and during peak stress $(\triangle \mathrm{LVEF})$ are helpful for detecting high-risk CAD. ${ }^{10,16-18}$ The available evidence suggests that in normal subjects and those with single-vessel disease, LVEF increases during peak vasodilator stress. ${ }^{10}$ In patients with high-risk CAD, however, the $\triangle \mathrm{LVEF}$ decreases. Consequently, $\triangle \mathrm{LVEF}$ could improve the detection of multivessel disease from $50 \%$ to $79 \%$.

The emerging prognostic data for PET perfusion imaging suggest that the presence of normal myocardial perfusion identifies patients at low risk for cardiovascular events, and that

Received October 3, 2014; revised manuscript received November 14, 2014; accepted November 20, 2014; released online December 18, 2014

Department of Cardiovascular Medicine (M.N., H.T.), Department of Nuclear Medicine (N.T.), Hokkaido University Graduate School of Medicine, Sapporo, Japan

Mailing address: Masanao Naya, MD, PhD, Department of Cardiovascular Medicine, Hokkaido University Graduate School of Medicine,

N-15, W-7, Kita-ku, Sapporo 060-8638, Japan. E-mail: naya@med.hokudai.ac.jp

ISSN-1346-9843 doi:10.1253/circj.CJ-14-1060

All rights are reserved to the Japanese Circulation Society. For permissions, please e-mail: cj@j-circ.or.jp 
A
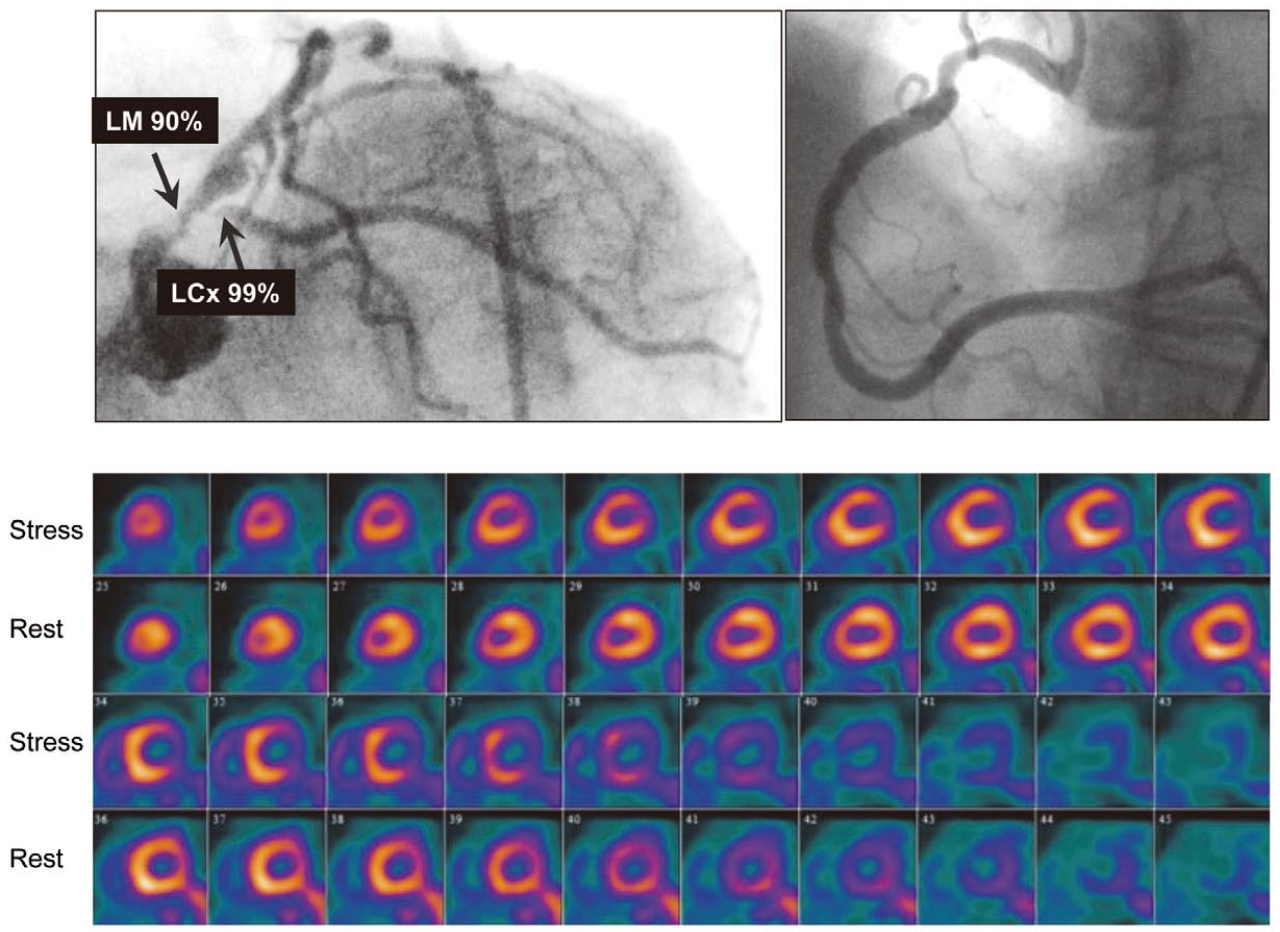

B

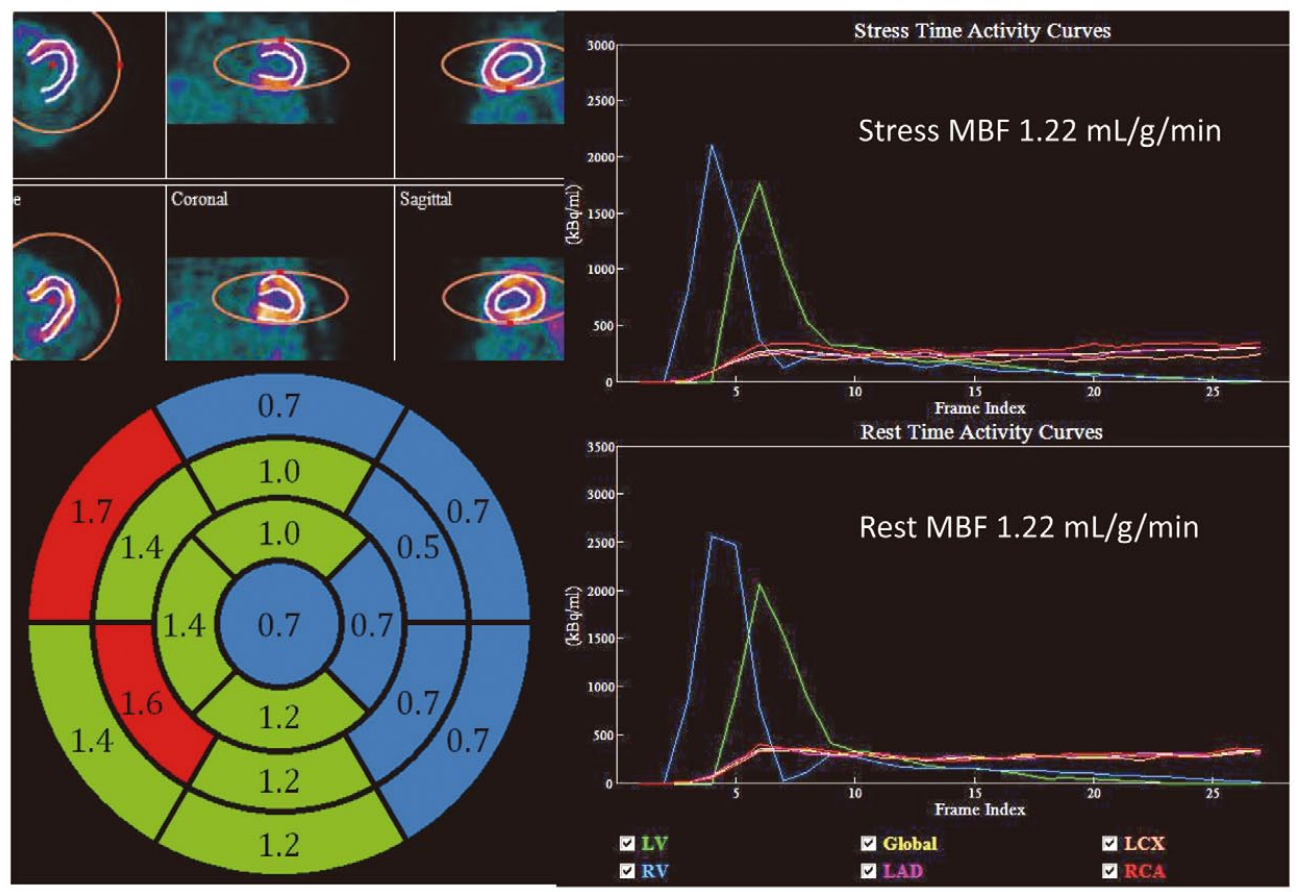

Figure 1. (A) Patient with high-risk anatomy marked by significant ischemia. (B) Time-activity curves and a polar map of 17-segment coronary flow reserve are shown. LAD, left anterior descending; LCX, left circumflex artery; LM, left main; LV, left ventricle; $\mathrm{MBF}$, myocardial blood flow; RCA, right coronary artery; RV, right ventricle. Reprinted with permission from (A) Naya M, et al ${ }^{41}$ and (B) Naya M. ${ }^{96}$

the risk increases linearly with increasing extent and severity of stress perfusion defects. ${ }^{6,19-21}$ Furthermore, recent studies have shown that measurements of CFR assessed by PET can also provide important prognostic information over semiquan- titative perfusion data. ${ }^{22-27}$ In patients with normal perfusion, abnormal CFR was independently associated with higher annual event rates over 3 years compared with normal CFR for cardiac events $(1.4 \%$ vs. $6.3 \% ; \mathrm{P}<0.05)$ and cardiac death 


\section{Per-vessel CFR and \%diameter stenosis}

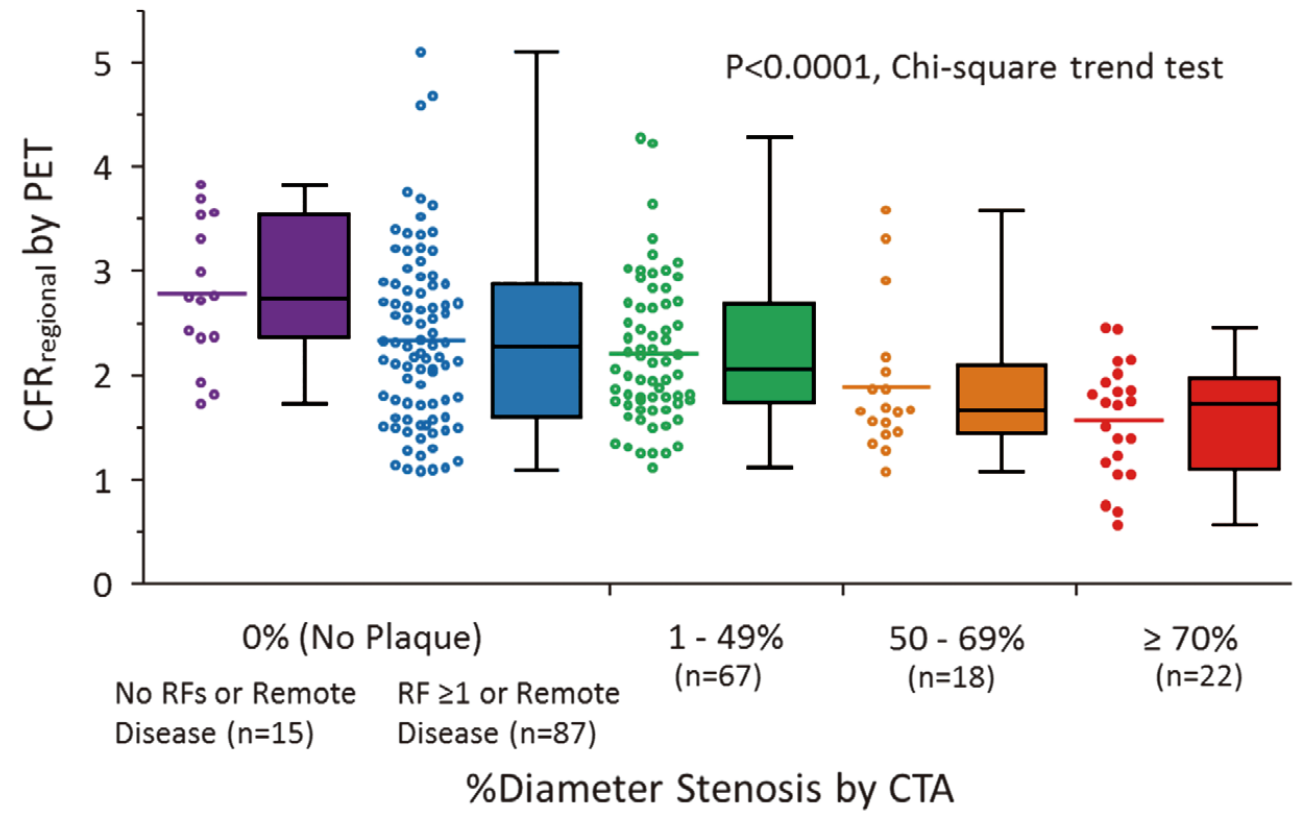

Figure 2. Scatter and box-and-whiskers plots demonstrating the distributions of per-vessel coronary flow reserve (CFR) in vessels with no plaque (patients with no risk factors (RFs) or remote disease; patients with RF $\geq 1$ or remote disease), and with 1-49\%, $50-69 \%$, and $\geq 70 \%$ diameter stenosis, respectively. If a patient has 1- or 2-vessel disease, the remote non-atherosclerotic vessels are classified as $0 \%$ stenosis with remote disease. From left to right, the data show a modest stepwise reduction in CFR with increasing stenosis severity. Of note, one-third of the regions supplied by non-obstructive stenosis had CFR <2.0, suggesting a high frequency of microvascular dysfunction in these patients with a high prevalence of coronary RFs. Reproduced with permission from Naya M, et al. ${ }^{40}$

$(0.5 \%$ vs. $3.1 \% ; \mathrm{P}<0.05) .{ }^{27}$

\section{Quantification of MBF From Serial Dynamic Scans of Perfusion Imaging}

PET dynamic scanning the moment of injection of tracer combines the very unique ability of nuclear medicine with wellvalidated methods of estimating absolute measurements of MBF in $\mathrm{ml} \cdot \mathrm{g}^{-1} \cdot \mathrm{min}^{-1}$ units and CFR ratio. ${ }^{28,29}$ This method is superior to SPECT perfusion scanning because list mode acquisition by PET enables us to assess time-activity curves without patient burden related to cost and radiation exposure. In patients with diffuse CAD and multivessel stenosis, measurement of CFR uncovers areas of the myocardium at risk with somewhat better detail than myocardial perfusion imaging. ${ }^{11}$ ATP, dipyridamole, regadenoson, and dobutamine are used as stress agents. These stressors as dependent variables are not informative to the multivariable model for predicting cardiac events, ${ }^{30}$ meaning that physicians can select the stressor according to each patient's condition for the estimation of CFR. Several kinetic models to estimate absolute MBF have been proposed, with improved repeatability. ${ }^{31-38}$ Previous study shows that the mean minus 2 standard deviations of CFR in young healthy controls is $2.2 .{ }^{39} \mathrm{In}$ fact, the best cutoff value to detect patients with CAD at high risk is $<2.0 .^{28,40}$

\section{A Case of Quantitative CFR ${ }^{41}$}

An 85-year-old woman with a history of hypertension and obesity was referred for evaluation of atypical chest pain. There was extensive and severe CAD involving the left main, proximal left anterior descending, and left circumflex coronary arteries (Figure 1A). The short-axis stress/rest myocardial perfusion images demonstrated transient ischemic dilation and a medium-sized but severe perfusion defect involving the lateral LV wall, which was completely reversible. After setting a region of interest on the $\mathrm{LV}$ wall, time-intensity curves of the LV wall and cavity were obtained. Absolute MBFs were estimated by a compartment model (Figure 1B). The 17-segment regional and global CFRs were computed by stressMBF/ restMBF. Ischemic territories had very low CFR (0.5-0.7). Importantly, low CFR (0.7-1.4) was observed not only in segments of presumably underestimated ischemic burden/severe coronary stenosis segments (downstream of left main disease) but also in no-ischemia/non-obstructive segments (right coronary artery).

\section{CFR as a Vascular Function in the Entire Coronary Circulation}

There is a growing body of data demonstrating an inverse relationship between coronary artery stenosis and CFR. ${ }^{40,42-46} \mathrm{~A}$ recent study showed that the per-patient anatomical disease severity calculated by the Duke CAD score is modestly associated with vasodilatory function in patients with CAD.$^{40} \mathrm{On}$ a per-patient basis, global CFR was a sensitive marker for the identification of patients with high-risk anatomic disease by 


\begin{tabular}{|c|c|c|c|c|c|}
\hline Study & Risk factor & No. of patients & $\begin{array}{c}\text { Rest MBF } \\
\left(\mathrm{ml} \cdot \mathrm{g}^{-1} \cdot \mathrm{min}^{-1}\right)\end{array}$ & $\begin{array}{l}\text { Stress MBF } \\
\left(\mathrm{ml} \cdot \mathrm{g}^{-1} \cdot \mathrm{min}^{-1}\right)\end{array}$ & $\begin{array}{c}\text { CFR } \\
\text { (ratio) }\end{array}$ \\
\hline Campisi et al62 & Smoking & 16 & 0.68 & 1.92 & 2.88 \\
\hline Iwado et al90 & Smoking & 18 & 0.86 & 3.20 & 3.78 \\
\hline Yokoyama et al91 & Diabetes (type 2) & 25 & 0.74 & 1.84 & 2.77 \\
\hline Di Carli et al 55 & Diabetes (type 2) & 17 & 0.92 & 2.47 & 2.52 \\
\hline Di Carli et al55 & Diabetes (type 1) & 18 & 0.96 & 2.52 & 2.47 \\
\hline Laine et al50 & $\mathrm{HT}$ & 16 & 0.83 & 2.02 & 2.85 \\
\hline Naya et a $\left.\right|^{52}$ & HT & 29 & 0.98 & 2.77 & 2.95 \\
\hline Yokoyama et al ${ }^{64}$ & Dyslipidemia & 11 & 0.70 & 2.1 & 3.0 \\
\hline Kaufmann et al63 & Dyslipidemia & 19 & 0.84 & 3.30 & 3.95 \\
\hline Di Carli et al ${ }^{58}$ & Metabolic syndrome & 181 & 0.80 & 1.94 & 2.5 \\
\hline Fukushima et al67 & CKD & 40 & 1.1 & 2.3 & 2.2 \\
\hline
\end{tabular}

ATP, adenosine triphosphate; CAD, coronary artery disease; CKD, chronic kidney disease; CRF, coronary flow reserve; $\mathrm{HT}$, hypertension; MBF, myocardial blood flow.

\begin{tabular}{|c|c|c|c|c|c|c|c|}
\hline Study & $\begin{array}{c}\text { Outcome measures } \\
\text { by angiography }\end{array}$ & $\begin{array}{l}\text { No. of patients } \\
\text { (outcome) }\end{array}$ & Pretest probability/RFs & $\begin{array}{l}\text { Cutoff of } \\
\text { CFR }\end{array}$ & Sensitivity & Specificity & AUC \\
\hline Naya et $\mathrm{al}^{40}$ & $\begin{array}{c}\text { Duke CAD index }{ }^{58} \\
\geq 50 \%\end{array}$ & $73(n=11)$ & $56 \%$ of patients had RFs $\geq 2$ & 2.1 & 1.0 & 0.55 & 0.78 \\
\hline Naya et al ${ }^{41}$ & $\begin{array}{l}\text { 2-VD with prox LAD, } \\
\text { 3-VD }(\% D S \geq 70 \%) \\
\text { or LM }(\geq 50 \%)\end{array}$ & $290(n=55)$ & Duke pretest $^{92}=52$ [IQR: 24-81] & 1.9 & 0.89 & 0.36 & 0.65 \\
\hline Kajander et al ${ }^{29}$ & $\begin{array}{l}\text { 1-VD }(n=17), \\
\geq 2-\operatorname{VD}(n=23)\end{array}$ & $107(n=40)$ & Diamond $^{93}=30-70 \%$ & $\begin{array}{c}\text { Peak } \\
\mathrm{MBF}=2.5\end{array}$ & 0.95 & 0.91 & 0.95 \\
\hline Ziadi et $\mathrm{al}^{28}$ & 3-VD (\%DS $\geq 70 \%)$ & $120(n=25)$ & $\begin{array}{c}\text { HT (68\%), DM (31\%), } \\
\text { smoking (68\%), } \\
\text { known CAD (64\%) }\end{array}$ & $\begin{array}{c}2.0,1.5 \\
1.0\end{array}$ & $\begin{array}{l}0.88,0.80 \\
\quad 0.36\end{array}$ & $\begin{array}{l}0.51,0.74 \\
0.96\end{array}$ & 0.82 \\
\hline Danad et al ${ }^{94}$ & $\begin{array}{c}\text { Per-vessel analysis } \\
\text { (\%DS } \geq 50 \%), \\
\text { 1-VD }(n=22), \\
\text { 2-VD }(n=12), \\
\text { 3-VD }(n=15)\end{array}$ & $120(n=49)$ & Diamond $=55 \pm 30 \%$ & 2.3 & 0.76 & 0.63 & 0.81 \\
\hline Morton et al ${ }^{95}$ & $\begin{array}{l}\text { Per-vessel analysis } \\
\quad(\% \mathrm{DS} \geq 70 \%)\end{array}$ & $38(n=25)$ & $\begin{array}{l}\mathrm{HT}(73 \%), \mathrm{DM}(32 \%), \\
\text { smoking }(12 \%)\end{array}$ & 1.44 & 0.82 & 0.87 & 0.83 \\
\hline
\end{tabular}

AUC, area under curve; DM, diabetes mellitus; DS, diameter stenosis; IQR, interquartile range; LAD, left anterior descending; LM, left main; $\mathrm{RFs}$, risk factors; VD, vessel disease.

CT angiography. In multivariable analyses including demographic data, coronary risk factors, and CT angiography data, only the modified Duke CAD index ${ }^{47}$ and the number of coronary segments with mixed plaque showed significant association with reduced CFR. On a per-vessel basis, there was also a clinically modest relationship between the stenosis severity by CT angiography and its downstream effect of CFR (Figure 2). This modest relationship between anatomy and coronary physiology suggests abnormal vascular reactivity during stress and diffuse atherosclerosis in the microvasculature. Thus, CFR is regulated not only by epicardial coronary artery stenosis and remodeling, but also by microvascular structures and density, endothelial-dependent and -independent vasodilation, ${ }^{48,49}$ and perfusion pressure.

\section{Abnormal CFR in Coronary Risk Factors}

There are many studies demonstrating that, even in patients without obstructive CAD, CFR is reduced under such conditions as hypertension, ${ }^{50-54}$ diabetes ${ }^{55-57}$ metabolic syndrome, ${ }^{58,59}$ smoking, ${ }^{39,60-62}$ dyslipidemia, ${ }^{63-66}$ chronic kidney disease,${ }^{67,68}$ and systemic inflammation ${ }^{69-71}$ compared with healthy volunteers (The average CFR in these studies is 3.8) (Table 1). These studies, as well as others, suggest that coronary microvascular dysfunction precedes the flow-limiting atherosclerotic plaque burden of epicardial coronary arteries in patients with risk factors. Therefore, CFR reduction $(<2.0)$ associated with cumulative coronary risk factors is present in up to $50 \%$ of a cohort of patients with suspected CAD and no evidence of ischemia. ${ }^{22}$ In a large cohort of non-obstructive CAD, stepwise multivariate linear regression showed $\beta$ estimates of the intercept (3.5), age $(-0.01)$, body mass index $(-0.02)$, hypertension $(-0.20)$, diabetes $(-0.24)$, hemodialysis $(-0.56)$, preoperative evaluation $(-0.26)$, and $\mathrm{EF}$ reserve $>0(0.03)$ to predict CFR value. ${ }^{72}$ The effect of sex on coronary microvascular dysfunction is another topic of interest because it is often recognized in females in whom angina pain is obvious without coronary stenosis. ${ }^{73}$ Murthy et al demonstrated that microvascular dysfunction (CFR <2.0) is observed in $>50 \%$ of both men and women without stress perfusion abnormalities. ${ }^{72} \mathrm{Im}$ portantly, the effects of low CFR on cardiac outcomes are equally observed in both sexes. 
Table 3. Prognostic Value of CFR After Adjustment by Clinical Variables, EF, and SSS

\begin{tabular}{|c|c|c|c|c|c|c|c|c|}
\hline Study & Cohort & $\begin{array}{l}\text { No. of patients } \\
\text { (outcome) }\end{array}$ & Endpoint & $\begin{array}{l}\text { Follow-up } \\
\text { (years) }\end{array}$ & Mean EF & $\begin{array}{c}\text { SSS } \\
\text { (medium [IQR]) }\end{array}$ & $\begin{array}{l}\text { Cutoff of } \\
\text { CFR }\end{array}$ & $\begin{array}{c}\text { Adjusted } \\
\text { hazard ratio }\end{array}$ \\
\hline Murthy et $\mathrm{al}^{82}$ & CAD & $2,783(n=137)$ & Cardiac death & 1.4 & $58 \%$ & 0 [0-10.3] & $\begin{array}{l}0-1.5,1.5-2.0 \\
>2.0 \text { (tertile) }\end{array}$ & $\begin{array}{l}\text { 5.6, 3.4, } \\
\text { Reference }\end{array}$ \\
\hline Ziadi et al ${ }^{24}$ & CAD & $677(n=71)$ & MACE & 1.1 & $53 \%$ & $\begin{array}{l}\geq 4 \\
0-3\end{array}$ & $<2.0$ (binary) & $\begin{array}{l}4.6 \\
2.4\end{array}$ \\
\hline Herzog et $\mathrm{al}^{27}$ & CAD & $256(n=29)$ & Cardiac death & 5.5 & Not available & - & $<2.0$ (binary) & 2.86 \\
\hline Tio et $\mathrm{al}^{26}$ & $\mathrm{ICM}$ & $344(n=60)$ & Cardiac death & 7.1 & $35 \%$ & - & Per 0.5 decrease & 4.1 \\
\hline $\begin{array}{l}\text { Fukushima } \\
\text { et al }{ }^{25}\end{array}$ & CAD & $224(n=33)$ & MACE & 1.0 & $60 \%$ & - & $<2.11$ (binary) & 2.9 \\
\hline Murthy et al ${ }^{83}$ & Diabetes & $1,172(n=78)$ & Cardiac death & 1.4 & $56 \%$ & $2.9[0-14.7]$ & <1.6 (binary) & 3.2 \\
\hline Murthy et $\mathrm{al}^{23}$ & CKD & $866(n=88)$ & Cardiac death & 1.3 & $54 \%$ & $0[0-7.4]$ & $<1.5$ (binary) & 2.1 \\
\hline Naya et al22 & No ischemia & $901(n=57)$ & MACE & 1.5 & $63 \%$ & Only 0-2 & $<2.0$ (binary) & 3.1 \\
\hline
\end{tabular}

$\mathrm{EF}$, ejection fraction; ICM, ischemic cardiomyopathy; MACE, major adverse cardiac events; SSS, summed stress score. Other abbreviations as in Table 1.

\section{Diabetes}

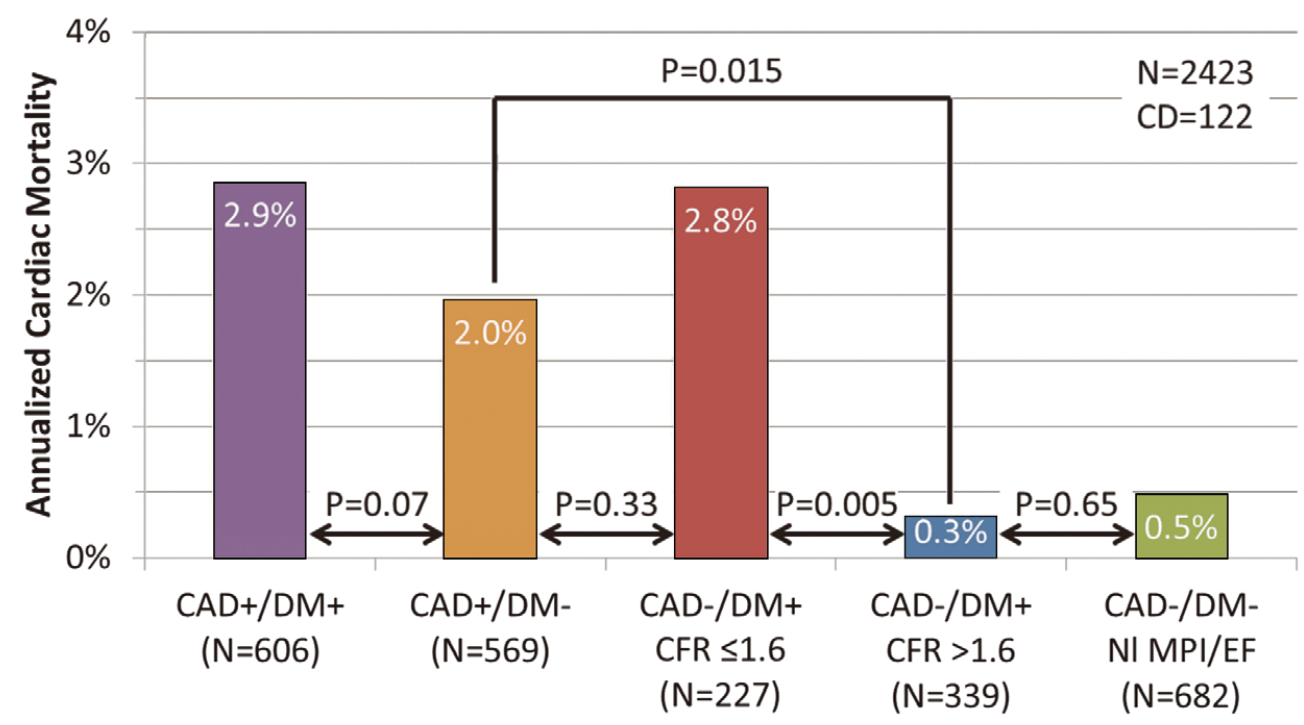

Figure 3. Risk-adjusted cardiac mortality. Patients with coronary artery disease (CAD) and diabetes mellitus (DM) have the highest risk (purple bar). In patients without CAD, preserved CFR (blue bar) is associated with low risk of cardiac death compared with those with abnormal CFR (red bar). CFR, coronary flow reserve. Reproduced with permission from Murthy VL, et al. ${ }^{83}$

There is the significant relationship between CFR (assessed by echocardiography or SPECT) and atherosclerotic burden and vascular function of peripheral arteries in non-obstructive CAD patients with coronary risk factors. These studies demonstrate that CFR is negatively associated with carotid intimamedia thickness ${ }^{74-78}$ and brachial-ankle pulse wave velocity, ${ }^{77,79}$ and positively with brachial flow-mediated dilation. ${ }^{75,76,80,81}$

\section{Diagnostic Value of CFR in CAD}

There are consistent data that CFR is useful in detecting CAD (Table 2). The latest large study examined the incremental diagnostic value over clinical risks, myocardial ischemia, transit ischemic dilation, $\triangle \mathrm{LVEF}$ during stress, and quantitative CFR. ${ }^{41}$ Taking into account the nature of CFR, preserved CFR was shown to be useful in confirming that coronary circulation is normal. Indeed, the presence of a normal global CFR (>1.93) in patients with normal or mildly-to-moderately abnormal myocardial perfusion scans (percent summed stress score $<10 \%$ ) is highly effective in excluding high-risk angiographic CAD (negative predictive value $=97 \%$ ). Although the severity of angiographic $\mathrm{CAD}$ is associated with a greater magnitude of inducible myocardial ischemia and reduced CFR, a significant proportion of patients with non-obstructive or even angiographically normal coronary arteries also show reduced CFR. Accordingly, the specificity of CFR to detect high-risk anatomy is very low (0.36). The addition of CFR to a model including clinical risk score and magnitude of inducible myocardial ischemia was shown to contribute modestly to the identification of high-risk angiographic $\mathrm{CAD}$, with an increase in the 


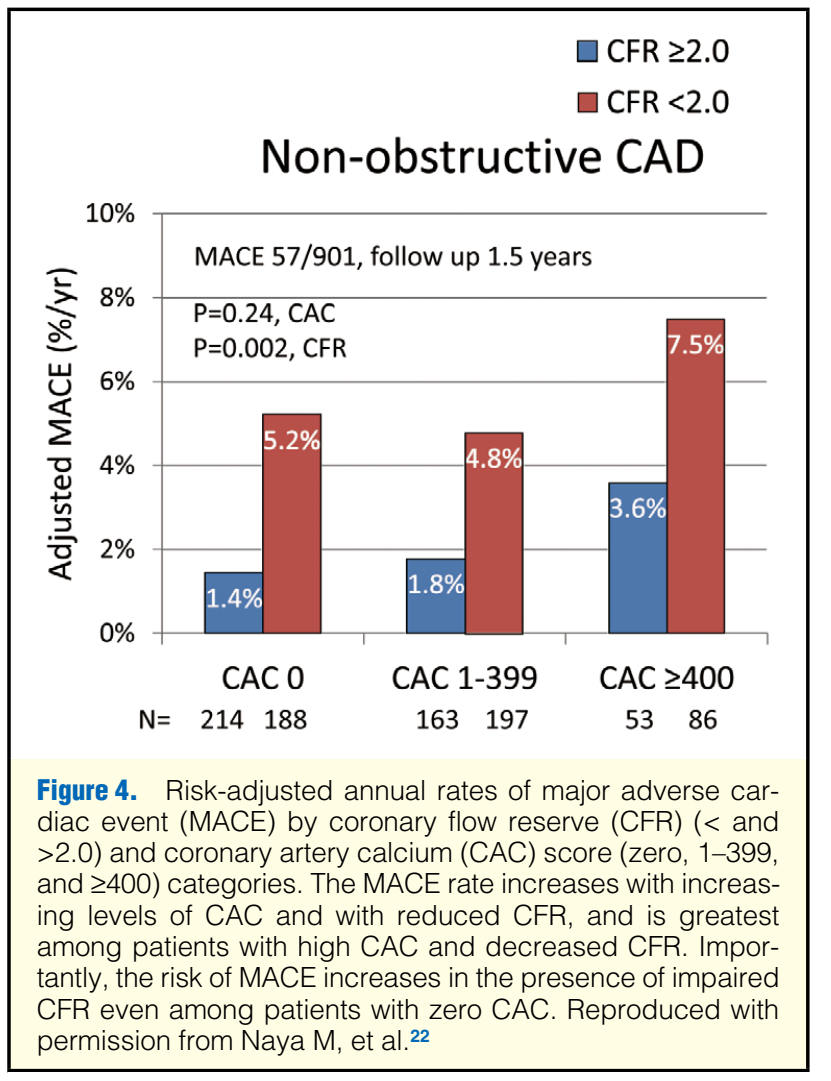

c-index from 0.687 to 0.731 in that study. Another study using per-patient CT angiography, severity counting per-patient coronary stenosis in magnitude and its location demonstrated that global CFR improved the identification of patients with high-risk coronary anatomy (Duke CAD index $\geq 50$ ), including those with 2-vessel CAD with proximal LAD stenosis $\geq 50 \%$ and 3-vessel CAD. ${ }^{40}$ A CFR $<2.0$ had a sensitivity of 0.91 and specificity of 0.58 for identifying high-risk CAD (receiveroperating characteristic (ROC) area $=0.78$ ). Similar values were obtained for the normal and relatively low-risk (summed stress score $\leq 3$ ) subgroups (ROC area $=0.93$ and 0.89 , respectively). Kajander et al demonstrated that the incorporation of CFR into CT angiography improved the diagnostic accuracy from $92 \%$ to $98 \%$ in relation to fractional flow reserve $<0.80$, as assessed by invasive coronary angiography. ${ }^{29}$

\section{Risk Stratification by CFR in CAD}

Recent studies, including large retrospective studies, consistently demonstrate that CFR is a significant prognostic marker besides ischemic and scar burden in patients with known and suspected CAD (Table 3). ${ }^{24-27,82}$ Low-risk patients classified by preserved CFR $(\geq 2.0)$ are associated with a true low risk for cardiac death $(0.2 \%$ per year). In contrast, high-risk patients stratified by very low $\mathrm{CFR}(\mathrm{CFR}<1.5)$ are at high risk of cardiac death (11\% per year). Because ischemic burden by stress perfusion imaging mainly reflects the coronary anatomy, the incorporation of microvascular disease activity associated with coronary risk factors into the ischemic burden im-
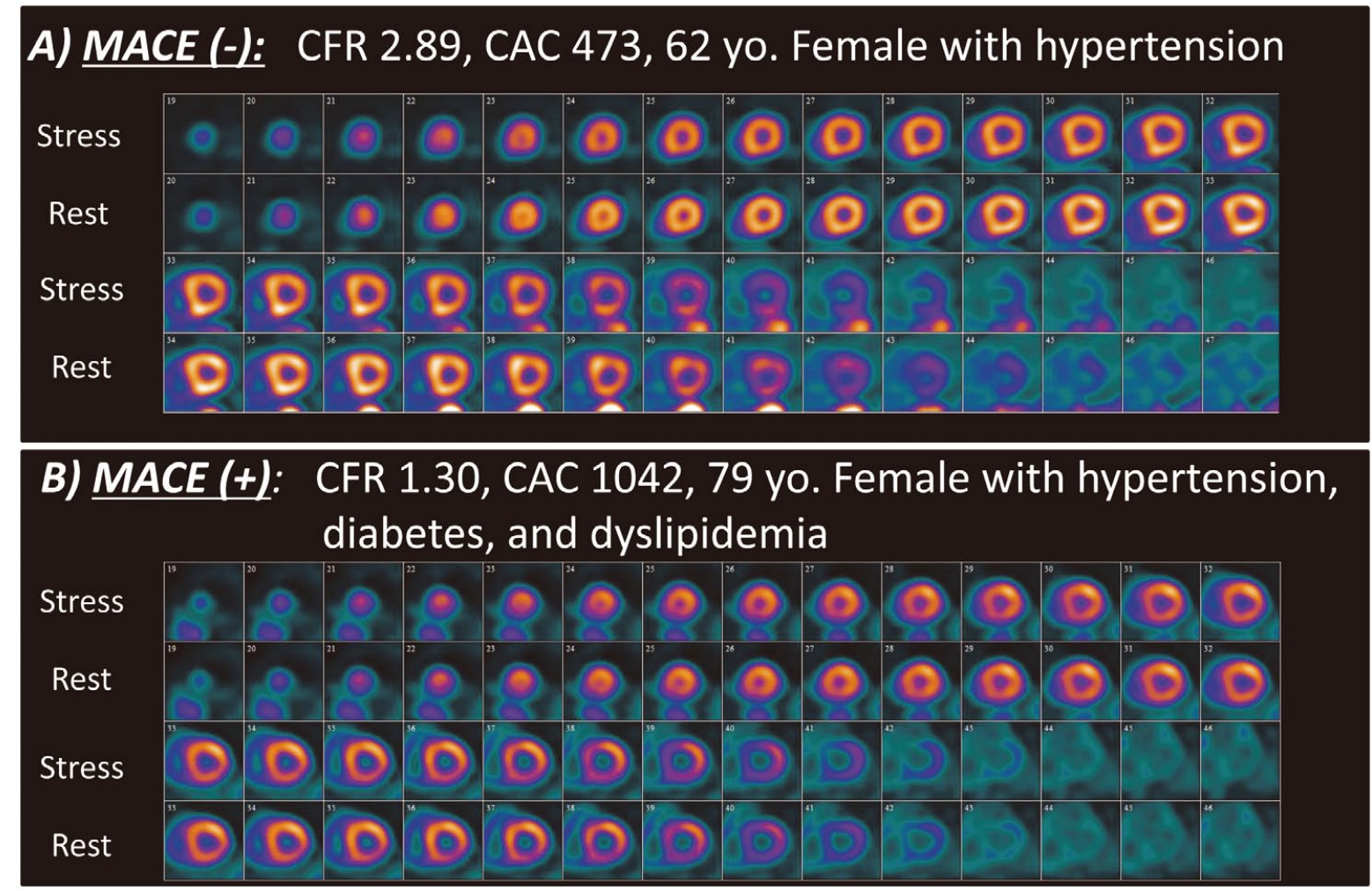

Figure 5. Two cases of non-obstructive coronary artery disease (CAD). Patient (A) has high coronary flow reserve (CFR) and patient (B) has a low CFR. CAC, coronary artery calcium; MACE, major adverse cardiac event. 
proves the risk stratification. CFR $<2.0$ is sensitive at detecting patients with poor cardiac outcomes in any category of ischemic burden with increased hazard ratio. ${ }^{24,25,82}$ Importantly, CFR reclassifies half of the intermediate-risk population (annualized cardiac death $=1-3 \%$ ) into the low- or high-risk group. ${ }^{82}$ Significant risk stratification by CFR was also verified in patients with diabetes mellitus (Figure 3$)^{83}$ and chronic kidney disease. ${ }^{23}$ Patients with diabetes and no CAD, but abnormal CFR (>1.6) had similar risk to those with both diabetes and CAD. In contrast, preserved CFR showed low risk even in patients with diabetes.

\section{Microvascular Function in Non-Obstructive CAD}

The total burden of coronary artery calcium (CAC) deposits is modestly associated with impaired vascular function in symptomatic patients without obstructive CAD ${ }^{84} \mathrm{~A}$ recent study also demonstrated that coronary microvascular dysfunction is present in up to $50 \%$ of symptomatic patients without CAD. ${ }^{22}$ Regarding cardiac events, both the extent of CAC deposits and the presence of coronary vascular dysfunction are associated with increased risk after adjustment for clinical risks. The presence of abnormal CFR was consistently associated with a higher rate of adverse cardiac events in each category of CAC severity (Figure 4). Indeed, even among patients with no calcium in their coronary arteries, impaired CFR was associated with higher rates of adjusted major adverse cardiac events (MACE: $1.4 \%$ vs. $4.8 \%, \mathrm{P}=0.03$ ). Accordingly, CFR helped reclassify risk in $44 \%$ of patients without obstructive CAD, with a large net improvement in risk classification among those at intermediate clinical risk. In contrast, CAC did not result in improved risk assessment after accounting for clinical risk in those symptomatic patients with a high burden of risk factors. These results suggest that direct measurement of coronary vasodilator function may be a clinically meaningful index of $\mathrm{CAD}$ in addition to the total burden of calcified atherosclerosis.

Regarding the treatment for abnormal CFR, many studies have demonstrated the beneficial effects of statins, ${ }^{66,85,86}$ angiotensin-converting enzyme inhibitors, ${ }^{87}$ and angiotensin II receptor blockers ${ }^{53,88}$ on CFR. Coronary revascularization may also improve CFR. ${ }^{89}$ The outcome effects of targeting improvement of CFR by optimal medical therapy and lifestyle modification need to be evaluated.

\section{Case Reports (High vs. Low CFR for Outcome)}

Two patients who underwent 82-rubidium PET and CAC scan CT are shown in Figure 5. Neither patient had ischemia, but both had high calcium scores. The patient with normal CFR had no cardiac events at 1.1 years after PET/CT examination, whereas the patient with low CFR died of non-cardiac cause in the 6 months after examination.

\section{Conclusions}

This review highlights the significance of quantitative CFR as an integrated index of coronary artery stenosis, diffuse atherosclerosis, and microvascular dilatory function. Normal CFR, indicating normal coronary circulation, is associated with low probability of coronary atherosclerosis and low risk of cardiac events. In contrast, abnormal CFR, indicating coronary microvascular disease activity either with the presence or absence of epicardial atherosclerosis, is a significant marker that can stratify CAD risk.

\section{References}

1. Yoshinaga K, Tomiyama Y, Suzuki E, Tamaki N. Myocardial blood flow quantification using positron-emission tomography: Analysis and practice in the clinical setting. Circ J 2013; 77: 1662-1671.

2. Ohira H, Mc Ardle B, Cocker MS, deKemp RA, Dasilva JN, Beanlands RS. Current and future clinical applications of cardiac positron emission tomography. Circ J 2013; 77: 836-848.

3. Sampson UK, Dorbala S, Limaye A, Kwong R, Di Carli MF. Diagnostic accuracy of rubidium- 82 myocardial perfusion imaging with hybrid positron emission tomography/computed tomography in the detection of coronary artery disease. J Am Coll Cardiol 2007; 49: $1052-1058$.

4. Hsiao E, Ali B, Blankstein R, Skali H, Ali T, Bruyere J Jr, et al. Detection of obstructive coronary artery disease using regadenoson stress and ${ }^{82} \mathrm{Rb}$ PET/CT myocardial perfusion imaging. J Nucl Med 2013; 54: $1748-1754$.

5. Dorbala S, Di Carli MF, Beanlands RS, Merhige ME, Williams BA, Veledar E, et al. Prognostic value of stress myocardial perfusion positron emission tomography: Results from a multicenter observational registry. J Am Coll Cardiol 2013; 61: 176-184.

6. Yoshinaga K, Chow BJ, Williams K, Chen L, deKemp RA, Garrard $\mathrm{L}$, et al. What is the prognostic value of myocardial perfusion imaging using rubidium-82 positron emission tomography? J Am Coll Cardiol 2006; 48: 1029-1039.

7. Naya M, Di Carli MF. Myocardial perfusion PET/CT to evaluate known and suspected coronary artery disease. Q J Nucl Med Mol Imaging 2010; 54: 145-156.

8. Jaarsma C, Leiner T, Bekkers SC, Crijns HJ, Wildberger JE, Nagel $\mathrm{E}$, et al. Diagnostic performance of noninvasive myocardial perfusion imaging using single-photon emission computed tomography, cardiac magnetic resonance, and positron emission tomography imaging for the detection of obstructive coronary artery disease: A meta-analysis. J Am Coll Cardiol 2012; 59: 1719-1728.

9. Rochitte CE, George RT, Chen MY, Arbab-Zadeh A, Dewey M, Miller JM, et al. Computed tomography angiography and perfusion to assess coronary artery stenosis causing perfusion defects by single photon emission computed tomography: The CORE320 study. Eur Heart J 2014; 35: 1120-1130.

10. Dorbala S, Vangala D, Sampson U, Limaye A, Kwong R, Di Carli MF. Value of vasodilator left ventricular ejection fraction reserve in evaluating the magnitude of myocardium at risk and the extent of angiographic coronary artery disease: A ${ }^{82} \mathrm{Rb}$ PET/CT study. J Nucl Med 2007; 48: 349-358.

11. Parkash R, deKemp RA, Ruddy TD, Kitsikis A, Hart R, Beauchesne $\mathrm{L}$, et al. Potential utility of rubidium 82 PET quantification in patients with 3-vessel coronary artery disease. J Nucl Cardiol 2004; 11: $440-449$.

12. Greenwood JP, Maredia N, Younger JF, Brown JM, Nixon J, Everett $\mathrm{CC}$, et al. Cardiovascular magnetic resonance and single-photon emission computed tomography for diagnosis of coronary heart disease (CE-MARC): A prospective trial. Lancet 2012; 379: $453-$ 460.

13. Schwitter J, Wacker CM, Wilke N, Al-Saadi N, Sauer E, Huettle K, et al. MR-IMPACT II: Magnetic Resonance Imaging for Myocardial Perfusion Assessment in Coronary artery disease Trial: Perfusion-cardiac magnetic resonance vs. single-photon emission computed tomography for the detection of coronary artery disease: A comparative multicentre, multivendor trial. Eur Heart J 2013; 34: $775-781$.

14. Dunet V, Qanadli SD, Allenbach G, Dabiri A, Mazzolai L, Waeber $\mathrm{B}$, et al. Assessment of coronary vasoreactivity by multidetector computed tomography: Feasibility study with rubidium- 82 cardiac positron emission tomography. Circ J 2012; 76: 160-167.

15. Kamiya K, Sakakibara M, Asakawa N, Yamada S, Yoshitani T, Iwano $\mathrm{H}$, et al. Cardiac magnetic resonance performs better in the detection of functionally significant coronary artery stenosis compared to single-photon emission computed tomography and dobutamine stress echocardiography. Circ J 2014; 78: 2468-2476.

16. Brown TL, Merrill J, Volokh L, Bengel FM. Determinants of the response of left ventricular ejection fraction to vasodilator stress in electrocardiographically gated (82)rubidium myocardial perfusion PET. Eur J Nucl Med Mol Imaging 2008; 35: 336-342.

17. Weiss AT, Berman DS, Lew AS, Nielsen J, Potkin B, Swan HJ, et al. Transient ischemic dilation of the left ventricle on stress thallium-201 scintigraphy: A marker of severe and extensive coronary artery disease. J Am Coll Cardiol 1987; 9: 752-759.

18. McLaughlin MG, Danias PG. Transient ischemic dilation: A powerful diagnostic and prognostic finding of stress myocardial perfusion imaging. J Nucl Cardiol 2002; 9: 663-667. 
19. Marwick TH, Shan K, Patel S, Go RT, Lauer MS. Incremental value of rubidium-82 positron emission tomography for prognostic assessment of known or suspected coronary artery disease. Am J Cardiol 1997; 80: $865-870$.

20. Dorbala S, Hachamovitch R, Curillova Z, Thomas D, Vangala D, Kwong RY, et al. Incremental prognostic value of gated $\mathrm{Rb}-82$ positron emission tomography myocardial perfusion imaging over clinical variables and rest LVEF. JACC Cardiovasc Imaging 2009; 2: $846-854$.

21. Lertsburapa K, Ahlberg AW, Bateman TM, Katten D, Volker L, Cullom SJ, et al. Independent and incremental prognostic value of left ventricular ejection fraction determined by stress gated rubidium 82 PET imaging in patients with known or suspected coronary artery disease. J Nucl Cardiol 2008; 15: 745-753.

22. Naya M, Murthy VL, Foster CR, Gaber M, Klein J, Hainer J, et al. Prognostic interplay of coronary artery calcification and underlying vascular dysfunction in patients with suspected coronary artery disease. J Am Coll Cardiol 2013; 61: 2098-2106.

23. Murthy VL, Naya M, Foster CR, Hainer J, Gaber M, Dorbala S, et al. Coronary vascular dysfunction and prognosis in patients with chronic kidney disease. JACC Cardiovasc Imaging 2012; 5: 10251034.

24. Ziadi MC, Dekemp RA, Williams KA, Guo A, Chow BJ, Renaud $\mathrm{JM}$, et al. Impaired myocardial flow reserve on rubidium-82 positron emission tomography imaging predicts adverse outcomes in patients assessed for myocardial ischemia. J Am Coll Cardiol 2011; 58: $740-748$.

25. Fukushima K, Javadi MS, Higuchi T, Lautamaki R, Merrill J, Nekolla $\mathrm{SG}$, et al. Prediction of short-term cardiovascular events using quantification of global myocardial flow reserve in patients referred for clinical ${ }^{82} \mathrm{Rb}$ PET perfusion imaging. J Nucl Med 2011; 52: $726-$ 732.

26. Tio RA, Dabeshlim A, Siebelink HM, de Sutter J, Hillege HL, Zeebregts CJ, et al. Comparison between the prognostic value of left ventricular function and myocardial perfusion reserve in patients with ischemic heart disease. J Nucl Med 2009; 50: 214-219.

27. Herzog BA, Husmann L, Valenta I, Gaemperli O, Siegrist PT, Tay FM, et al. Long-term prognostic value of ${ }^{13} \mathrm{~N}$-ammonia myocardial perfusion positron emission tomography added value of coronary flow reserve. J Am Coll Cardiol 2009; 54: 150-156.

28. Ziadi MC, Dekemp RA, Williams K, Guo A, Renaud JM, Chow BJ, et al. Does quantification of myocardial flow reserve using rubidium-82 positron emission tomography facilitate detection of multivessel coronary artery disease? J Nucl Cardiol 2012; 19: 670-680.

29. Kajander S, Joutsiniemi E, Saraste M, Pietila M, Ukkonen H, Saraste A, et al. Cardiac positron emission tomography/computed tomography imaging accurately detects anatomically and functionally significant coronary artery disease. Circulation 2010; 122: 603-613.

30. Naya M, Murthy VL, Di Carli MF. All vasodilators are not equal [Reply]. J Am Coll Cardiol 2013; 62: 1129.

31. Katoh C, Morita K, Shiga T, Kubo N, Nakada K, Tamaki N. Improvement of algorithm for quantification of regional myocardial blood flow using ${ }^{15} \mathrm{O}$-water with PET. J Nucl Med 2004; 45: 1908 1916.

32. Katoh C, Yoshinaga K, Klein R, Kasai K, Tomiyama Y, Manabe O, et al. Quantification of regional myocardial blood flow estimation with three-dimensional dynamic rubidium-82 PET and modified spillover correction model. J Nucl Cardiol 2012; 19: 763-774.

33. El Fakhri G, Sitek A, Guerin B, Kijewski MF, Di Carli MF, Moore SC. Quantitative dynamic cardiac ${ }^{82} \mathrm{Rb}$ PET using generalized factor and compartment analyses. J Nucl Med 2005; 46: 1264-1271.

34. Yoshida K, Mullani N, Gould KL. Coronary flow and flow reserve by PET simplified for clinical applications using rubidium- 82 or nitrogen-13-ammonia. J Nucl Med 1996; 37: 1701-1712.

35. Lortie M, Beanlands RS, Yoshinaga K, Klein R, Dasilva JN, DeKemp RA. Quantification of myocardial blood flow with ${ }^{82} \mathrm{Rb}$ dynamic PET imaging. Eur J Nucl Med Mol Imaging 2007; 34: 1765-1774.

36. Prior JO, Allenbach G, Valenta I, Kosinski M, Burger C, Verdun FR, et al. Quantification of myocardial blood flow with ${ }^{82} \mathrm{Rb}$ positron emission tomography: Clinical validation with ${ }^{15} \mathrm{O}$-water. Eur J Nucl Med Mol Imaging 2012; 39: 1037-1047.

37. Manabe O, Yoshinaga K, Katoh C, Naya M, deKemp RA, Tamaki N. Repeatability of rest and hyperemic myocardial blood flow measurements with ${ }^{82} \mathrm{Rb}$ dynamic PET. J Nucl Med 2009; 50: 68-71.

38. El Fakhri G, Kardan A, Sitek A, Dorbala S, Abi-Hatem N, Lahoud $\mathrm{Y}$, et al. Reproducibility and accuracy of quantitative myocardial blood flow assessment with (82)Rb PET: Comparison with (13)Nammonia PET. J Nucl Med 2009; 50: 1062-1071.

39. Naya M, Morita K, Yoshinaga K, Manabe O, Goto D, Hirata K, et al. Long-term smoking causes more advanced coronary endothelial dysfunction in middle-aged smokers compared to young smokers. Eur J Nucl Med Mol Imaging 2011; 38: 491-498.

40. Naya M, Murthy VL, Blankstein R, Sitek A, Hainer J, Foster C, et al. Quantitative relationship between the extent and morphology of coronary atherosclerotic plaque and downstream myocardial perfusion. J Am Coll Cardiol 2011; 58: 1807-1816.

41. Naya M, Murthy VL, Taqueti VR, Foster CR, Klein J, Garber M, et al. Preserved coronary flow reserve effectively excludes high-risk coronary artery disease on angiography. J Nucl Med 2014; 55: 248 255.

42. Uren NG, Melin JA, De Bruyne B, Wijns W, Baudhuin T, Camici PG. Relation between myocardial blood flow and the severity of coronary-artery stenosis. N Engl J Med 1994; 330: 1782-1788.

43. Di Carli M, Czernin J, Hoh CK, Gerbaudo VH, Brunken RC, Huang $\mathrm{SC}$, et al. Relation among stenosis severity, myocardial blood flow, and flow reserve in patients with coronary artery disease. Circulation 1995; 91: 1944-1951.

44. Anagnostopoulos C, Almonacid A, El Fakhri G, Curillova Z, Sitek A, Roughton M, et al. Quantitative relationship between coronary vasodilator reserve assessed by ${ }^{82} \mathrm{Rb}$ PET imaging and coronary artery stenosis severity. Eur J Nucl Med Mol Imaging 2008; 35: $1593-1601$.

45. Tsukamoto T, Morita K, Naya M, Katoh C, Inubushi M, Kuge Y, et al. Myocardial flow reserve is influenced by both coronary artery stenosis severity and coronary risk factors in patients with suspected coronary artery disease. Eur J Nucl Med Mol Imaging 2006; 33: $1150-1156$.

46. Beanlands RS, Muzik O, Melon P, Sutor R, Sawada S, Muller D, et al. Noninvasive quantification of regional myocardial flow reserve in patients with coronary atherosclerosis using nitrogen-13 ammonia positron emission tomography: Determination of extent of altered vascular reactivity. J Am Coll Cardiol 1995; 26: 1465-1475.

47. Miller JM, Rochitte CE, Dewey M, Arbab-Zadeh A, Niinuma H, Gottlieb I, et al. Diagnostic performance of coronary angiography by 64-row CT. N Engl J Med 2008; 359: 2324-2336.

48. Zeiher AM, Drexler H, Wollschlager H, Just H. Endothelial dysfunction of the coronary microvasculature is associated with coronary blood flow regulation in patients with early atherosclerosis. Circulation 1991; 84: 1984-1992.

49. Zeiher AM, Eigler N, Wollschlager H, Just H. Validation of a digital angiographic model to quantitate autoregulatory vasodilation of the coronary system. Eur Heart J 1989; 10(Suppl F): 66-72.

50. Laine H, Raitakari OT, Niinikoski H, Pitkanen OP, Iida H, Viikari J, et al. Early impairment of coronary flow reserve in young men with borderline hypertension. J Am Coll Cardiol 1998; 32: 147-153.

51. Masuda D, Nohara R, Tamaki N, Hosokawa R, Inada H, Hikai T, et al. Evaluation of coronary blood flow reserve by ${ }^{13} \mathrm{~N}^{-\mathrm{NH}_{3}}$ positron emission computed tomography (PET) with dipyridamole in the treatment of hypertension with the ACE inhibitor (Cilazapril). Ann Nucl Med 2000; 14: 353-360.

52. Naya M, Tsukamoto T, Inubushi M, Morita K, Katoh C, Furumoto $\mathrm{T}$, et al. Elevated plasma plasminogen activator inhibitor type-1 is an independent predictor of coronary microvascular dysfunction in hypertension. Circ J 2007; 71: 348-353.

53. Higuchi T, Abletshauser C, Nekolla SG, Schwaiger M, Bengel FM. Effect of the angiotensin receptor blocker Valsartan on coronary microvascular flow reserve in moderately hypertensive patients with stable coronary artery disease. Microcirculation 2007; 14: 805-812.

54. Prior JO, Quinones MJ, Hernandez-Pampaloni M, Facta AD, Schindler TH, Sayre JW, et al. Coronary circulatory dysfunction in insulin resistance, impaired glucose tolerance, and type 2 diabetes mellitus. Circulation 2005; 111: 2291-2298.

55. Di Carli MF, Janisse J, Grunberger G, Ager J. Role of chronic hyperglycemia in the pathogenesis of coronary microvascular dysfunction in diabetes. J Am Coll Cardiol 2003; 41: 1387-1393.

56. Yokoyama I, Ohtake T, Momomura S, Yonekura K, Woo-Soo S, Nishikawa $\mathbf{J}$, et al. Hyperglycemia rather than insulin resistance is related to reduced coronary flow reserve in NIDDM. Diabetes 1998; 47: $119-124$.

57. Schindler TH, Cadenas J, Facta AD, Li Y, Olschewski M, Sayre J, et al. Improvement in coronary endothelial function is independently associated with a slowed progression of coronary artery calcification in type 2 diabetes mellitus. Eur Heart J 2009; 30: 3064-3073.

58. Di Carli MF, Charytan D, McMahon GT, Ganz P, Dorbala S, Schelbert HR. Coronary circulatory function in patients with the metabolic syndrome. J Nucl Med 2011; 52: 1369-1377.

59. Teragawa H, Morita K, Shishido H, Otsuka N, Hirokawa Y, Chayama $\mathrm{K}$, et al. Impaired myocardial blood flow reserve in subjects with metabolic syndrome analyzed using positron emission tomography and N-13 labeled ammonia. Eur J Nucl Med Mol Imaging 2010; 37: 
$368-376$.

60. Morita K, Tsukamoto T, Naya M, Noriyasu K, Inubushi M, Shiga T, et al. Smoking cessation normalizes coronary endothelial vasomotor response assessed with ${ }^{15} \mathrm{O}$-water and PET in healthy young smokers. J Nucl Med 2006; 47: 1914-1920.

61. Campisi R, Czernin J, Schoder H, Sayre JW, Schelbert HR. L-Arginine normalizes coronary vasomotion in long-term smokers. Circulation 1999; 99: 491-497.

62. Campisi R, Czernin J, Schoder H, Sayre JW, Marengo FD, Phelps $\mathrm{ME}$, et al. Effects of long-term smoking on myocardial blood flow, coronary vasomotion, and vasodilator capacity. Circulation 1998; 98: $119-125$.

63. Kaufmann PA, Gnecchi-Ruscone T, Schafers KP, Luscher TF, Camici PG. Low density lipoprotein cholesterol and coronary microvascular dysfunction in hypercholesterolemia. J Am Coll Cardiol 2000; 36: 103-109.

64. Yokoyama I, Ohtake T, Momomura S, Nishikawa J, Sasaki Y, Omata M. Reduced coronary flow reserve in hypercholesterolemic patients without overt coronary stenosis. Circulation 1996; 94: 3232-3238.

65. Yokoyama I, Murakami T, Ohtake T, Momomura S, Nishikawa J, Sasaki Y, et al. Reduced coronary flow reserve in familial hypercholesterolemia. J Nucl Med 1996; 37: 1937-1942.

66. Baller D, Notohamiprodjo G, Gleichmann U, Holzinger J, Weise R, Lehmann J. Improvement in coronary flow reserve determined by positron emission tomography after 6 months of cholesterol-lowering therapy in patients with early stages of coronary atherosclerosis. Circulation 1999; 99: 2871-2875.

67. Fukushima K, Javadi MS, Higuchi T, Bravo PE, Chien D, Lautamaki $\mathrm{R}$, et al. Impaired global myocardial flow dynamics despite normal left ventricular function and regional perfusion in chronic kidney disease: A quantitative analysis of clinical ${ }^{82} \mathrm{Rb}$ PET/CT studies. $J$ Nucl Med 2012; 53: 887-893.

68. Charytan DM, Shelbert HR, Di Carli MF. Coronary microvascular function in early chronic kidney disease. Circ Cardiovasc Imaging 2010; 3: 663-671.

69. Naya M, Tsukamoto T, Morita K, Katoh C, Furumoto T, Fujii S, et al. Plasma interleukin- 6 and tumor necrosis factor-alpha can predict coronary endothelial dysfunction in hypertensive patients. Hypertens Res 2007; 30: 541-548.

70. Schindler TH, Nitzsche EU, Olschewski M, Magosaki N, Mix M, Prior JO, et al. Chronic inflammation and impaired coronary vasoreactivity in patients with coronary risk factors. Circulation 2004; 110: 1069-1075.

71. Recio-Mayoral A, Rimoldi OE, Camici PG, Kaski JC. Inflammation and microvascular dysfunction in cardiac syndrome $\mathrm{X}$ patients without conventional risk factors for coronary artery disease. JACC Cardiovasc Imaging 2013; 6: 660-667.

72. Murthy VL, Naya M, Taqueti VR, Foster CR, Gaber M, Hainer J, et al. Effects of sex on coronary microvascular dysfunction and cardiac outcomes. Circulation 2014; 129: 2518-2527.

73. Pepine CJ, Anderson RD, Sharaf BL, Reis SE, Smith KM, Handberg EM, et al. Coronary microvascular reactivity to adenosine predicts adverse outcome in women evaluated for suspected ischemia results from the National Heart, Lung and Blood Institute WISE (Women's Ischemia Syndrome Evaluation) study. J Am Coll Cardiol 2010; 55: $2825-2832$.

74. Takiuchi S, Rakugi H, Fujii H, Kamide K, Horio T, Nakatani S, et al. Carotid intima-media thickness is correlated with impairment of coronary flow reserve in hypertensive patients without coronary artery disease. Hypertens Res 2003; 26: 945-951.

75. Campuzano R, Moya JL, Garcia-Lledo A, Tomas JP, Ruiz S, Megias $\mathrm{A}$, et al. Endothelial dysfunction, intima-media thickness and coronary reserve in relation to risk factors and Framingham score in patients without clinical atherosclerosis. J Hypertens 2006; 24: 1581 1588 .

76. Gullu H, Erdogan D, Caliskan M, Tok D, Yildirim E, Ulus T, et al. Interrelationship between noninvasive predictors of atherosclerosis: Transthoracic coronary flow reserve, flow-mediated dilation, carotid intima-media thickness, aortic stiffness, aortic distensibility, elastic modulus, and brachial artery diameter. Echocardiography 2006; 23: $835-842$.

77. Tzortzis S, Ikonomidis I, Lekakis J, Papadopoulos C, Triantafyllidi $\mathrm{H}$, Parissis J, et al. Incremental predictive value of carotid intimamedia thickness to arterial stiffness for impaired coronary flow reserve in untreated hypertensives. Hypertens Res 2010; 33: 367-373.

78. Danad I, Raijmakers PG, Kamali P, Harms HJ, de Haan S, Lubberink
$\mathrm{M}$, et al. Carotid artery intima-media thickness, but not coronary artery calcium, predicts coronary vascular resistance in patients evaluated for coronary artery disease. Eur Heart J Cardiovasc Imaging 2012; 13: 317-323.

79. Fukuda D, Yoshiyama M, Shimada K, Yamashita H, Ehara S, Nakamura Y, et al. Relation between aortic stiffness and coronary flow reserve in patients with coronary artery disease. Heart 2006; 92: 759-762.

80. Pellegrino T, Storto G, Filardi PP, Sorrentino AR, Silvestro A, Petretta M, et al. Relationship between brachial artery flow-mediated dilation and coronary flow reserve in patients with peripheral artery disease. J Nucl Med 2005; 46: 1997-2002.

81. Park CS, Youn HJ, Kim JH, Cho EJ, Jung HO, Jeon HK, et al. Relation between peripheral vascular endothelial function and coronary flow reserve in patients with chest pain and normal coronary angiogram. Int J Cardiol 2006; 113: 118-120.

82. Murthy VL, Naya M, Foster CR, Hainer J, Gaber M, Di Carli G, et al. Improved cardiac risk assessment with noninvasive measures of coronary flow reserve. Circulation 2011; 124: 2215-2224.

83. Murthy VL, Naya M, Foster CR, Gaber M, Hainer J, Klein J, et al. Association between coronary vascular dysfunction and cardiac mortality in patients with and without diabetes mellitus. Circulation 2012; 126: $1858-1868$.

84. Curillova Z, Yaman BF, Dorbala S, Kwong RY, Sitek A, El Fakhri $\mathrm{G}$, et al. Quantitative relationship between coronary calcium content and coronary flow reserve as assessed by integrated PET/CT imaging. Eur J Nucl Med Mol Imaging 2009; 36: 1603-1610.

85. Takagi A, Tsurumi Y, Ishizuka N, Omori H, Arai K, Hagiwara N, et al. Single administration of cerivastatin, an HMG-CoA reductase inhibitor, improves the coronary flow velocity reserve: A transthoracic Doppler echocardiography study. Heart Vessels 2006; 21: 298-301.

86. Fujimoto K, Hozumi T, Watanabe H, Shimada K, Takeuchi M, Sakanoue Y, et al. Effect of fluvastatin therapy on coronary flow reserve in patients with hypercholesterolemia. Am J Cardiol 2004; 93: 1419-1421, A1410.

87. Schneider CA, Voth E, Moka D, Baer FM, Melin J, Bol A, et al. Improvement of myocardial blood flow to ischemic regions by angiotensin-converting enzyme inhibition with quinaprilat IV: A study using $\left[{ }^{15} \mathrm{O}\right]$ water dobutamine stress positron emission tomography. J Am Coll Cardiol 1999; 34: 1005-1011.

88. Akinboboye OO, Chou RL, Bergmann SR. Augmentation of myocardial blood flow in hypertensive heart disease by angiotensin antagonists: A comparison of lisinopril and losartan. J Am Coll Cardiol 2002; 40: 703-709.

89. Piek JJ, Boersma E, Voskuil M, di Mario C, Schroeder E, Vrints C, et al. The immediate and long-term effect of optimal balloon angioplasty on the absolute coronary blood flow velocity reserve: A subanalysis of the DEBATE study [Doppler Endpoints Balloon Angioplasty Trial Europe]. Eur Heart J 2001; 22: 1725-1732.

90. Iwado Y, Yoshinaga K, Furuyama H, Ito Y, Noriyasu K, Katoh C, et al. Decreased endothelium-dependent coronary vasomotion in healthy young smokers. Eur J Nucl Med Mol Imaging 2002; 29: 984-990.

91. Yokoyama I, Momomura S, Ohtake T, Yonekura K, Nishikawa J, Sasaki Y, et al. Reduced myocardial flow reserve in non-insulindependent diabetes mellitus. J Am Coll Cardiol 1997; 30: $1472-$ 1477.

92. Pryor DB, Shaw L, McCants CB, Lee KL, Mark DB, Harrell FE Jr, et al. Value of the history and physical in identifying patients at increased risk for coronary artery disease. Ann Intern Med 1993; 118: $81-90$.

93. Diamond GA, Forrester JS. Analysis of probability as an aid in the clinical diagnosis of coronary-artery disease. N Engl J Med 1979; 300: $1350-1358$.

94. Danad I, Raijmakers PG, Appelman YE, Harms HJ, de Haan S, van den Oever ML, et al. Hybrid imaging using quantitative $\mathrm{H}_{2}{ }^{15} \mathrm{O}$ PET and CT-based coronary angiography for the detection of coronary artery disease. J Nucl Med 2013; 54: 55-63.

95. Morton G, Chiribiri A, Ishida M, Hussain ST, Schuster A, Indermuehle A, et al. Quantification of absolute myocardial perfusion in patients with coronary artery disease: Comparison between cardiovascular magnetic resonance and positron emission tomography. J Am Coll Cardiol 2012; 60: 1546-1555.

96. Naya M. PET for the diagnosis of cardiomyopathy. Heart View 2013; 17: 40-45 (in Japanese). 